\title{
WestVirginiaUniversity
}

THE RESEARCH REPOSITORY @ WVU

Graduate Theses, Dissertations, and Problem Reports

2018

\section{Best Practices for Sepsis Patients: A Quality Improvement Project}

Kevin Mark Smith Jr

wvu, kvsmith1@hsc.wvu.edu

Follow this and additional works at: https://researchrepository.wvu.edu/etd

Part of the Nursing Administration Commons

\section{Recommended Citation}

Smith, Kevin Mark Jr, "Best Practices for Sepsis Patients: A Quality Improvement Project" (2018).

Graduate Theses, Dissertations, and Problem Reports. 3689.

https://researchrepository.wvu.edu/etd/3689

This Dissertation is protected by copyright and/or related rights. It has been brought to you by the The Research Repository @ WVU with permission from the rights-holder(s). You are free to use this Dissertation in any way that is permitted by the copyright and related rights legislation that applies to your use. For other uses you must obtain permission from the rights-holder(s) directly, unless additional rights are indicated by a Creative Commons license in the record and/ or on the work itself. This Dissertation has been accepted for inclusion in WVU Graduate Theses, Dissertations, and Problem Reports collection by an authorized administrator of The Research Repository @ WVU.

For more information, please contact researchrepository@mail.wvu.edu. 
Best Practices for Sepsis Patients: A Quality Improvement Project

\author{
Kevin Mark Smith Jr \\ Doctoral Research Project submitted \\ to the School of Nursing \\ at West Virginia University \\ in partial fulfillment of the requirement for the degree of \\ Doctor of Nursing Practice \\ Roger Carpenter, PhD, RN, NE-BC, CNE, Chair \\ Toni Dichiacchio, DNP, APRN, FNP-BC, CEN, FAANP \\ Mary Fanning, DNP, RN, FRE, NEA-BC \\ Department of Nursing
} Morgantown, West Virginia 2018

Keywords: Sepsis, Quality Improvement, Best Practice, Evidence Based Practice Copyright 2018, Kevin Mark Smith Jr 


\begin{abstract}
Best Practices for Sepsis Patients: A Quality Improvement Project
\end{abstract}

\author{
Kevin Mark Smith Jr
}

Sepsis is a complication caused by the overwhelming and life-threatening response of the body to an infection. Sepsis can lead to tissue damage, organ failure, and death (Center for Disease Control and Prevention, 2016). Sepsis is the leading cause of death in U.S. hospitals. Mortality from sepsis increases $8 \%$ for every hour that treatment is delayed. Each year, 258,000 people die from sepsis in the U.S. As many as $80 \%$ of sepsis deaths could be prevented with rapid diagnosis and treatment (Sepsis Alliance, 2016). This project seeks to improve the ability of the transfer unit to screen patients, improve early recognition and evaluation of best practices, and provide a connection with a provider for care consultation. This potential significance of this project is to improve patient outcomes including mortality, length of stay, and the assignment of patients to the appropriate level of care through early recognition of sepsis and the implementation of best practices. The use of a screening process to identify abnormal patient variables including elevated serum lactate, decreased blood pressure, elevated respiratory rate, and altered mental status can identify an increased likelihood of sepsis. 
Introduction $\quad 1$

Background 1

Problem Statement 1

Purpose of the Project 2

Significance of the Proposed Project 2

Literature Review and Synthesis 3

Issues of Sepsis in Hospitals $\quad 4$

Impact of Sepsis Screening on Recognition 4

and Implementation of Best Practices

$\begin{array}{ll}\text { Evidenced Based Practice for Sepsis Care } & 6\end{array}$

Bundles and Protocols $\quad 6$

$\begin{array}{ll}\text { SIRS Criteria } & 7\end{array}$

QSOFA and the Development of Screening Tools 8

$\begin{array}{ll}\text { Synthesis } & 9\end{array}$

$\begin{array}{ll}\text { Theoretical Framework } & 10\end{array}$

$\begin{array}{ll}\text { Project } & 10\end{array}$

$\begin{array}{ll}\text { Description and Design } & 10\end{array}$

$\begin{array}{ll}\text { Pilot Study } & 11\end{array}$

Fit of Theoretical Framework to Project 11

$\begin{array}{lr}\text { Feasibility Analysis } & 12\end{array}$

$\begin{array}{ll}\text { Project resources } & 12\end{array}$ 
Congruence to the strategic plan of the organization $\quad 14$

$\begin{array}{ll}\text { Evidence of key site support } & 14\end{array}$

$\begin{array}{ll}\text { Project timeline } & 15\end{array}$

$\begin{array}{lr}\text { Measurable Project Aims and Objectives } & 15\end{array}$

$\begin{array}{ll}\text { Evaluation Plan } & 17\end{array}$

$\begin{array}{ll}\text { Results } & 21\end{array}$

Aim 1: Evaluate the Usefulness of a New Sepsis Screening Process 23

Aim 2: Evaluate the Impact of the New Sepsis Screening Process 27

$\begin{array}{ll}\text { Discussion and Recommendations } & 29\end{array}$

$\begin{array}{ll}\text { Theoretical Framework } & 29\end{array}$

Clinical Significance of Study Findings 31

Recommendations for the Site $\quad 32$

Recommendations for Other Settings 33

Attainment of DNP Essentials $\quad 34$

$\begin{array}{ll}\text { Appendices } & 37\end{array}$ 


\section{Index of Appendices}

Appendix A: Sepsis Screening Process Algorithm 37

Appendix B: Theoretical Framework 39

Appendix C: Sepsis Screening Process Education $\quad 40$

Appendix D: Budget Table $\quad 42$

Appendix E: Gantt Chart $\quad 44$

Appendix F: Statistical Analysis $\quad 45$

$\begin{array}{ll}\text { References } & 47\end{array}$ 


\section{Introduction}

This project seeks to improve the process of care delivery for patients transferring to an Academic Medical Center with a diagnosis of sepsis. The staff of the transfer unit at the Academic Medical Center have recognized delays in transfers of patients with sepsis and inconsistencies in sepsis care delivery by sending facilities. The planned project is designed to improve the transfer process for these patients by implementing a new sepsis screening tool and providing sepsis consultation for outside facilities upon a positive sepsis screen. The objective of this project is to support timely evidence based care prior to patient transfer and subsequently improve patient outcomes.

\section{Background}

Sepsis is a complication caused by the overwhelming and life-threatening response of the body to an infection. Sepsis can lead to tissue damage, organ failure, and death (Center for Disease Control and Prevention, 2016). Sepsis is the leading cause of death in U.S. hospitals. Mortality from sepsis increases $8 \%$ for every hour that treatment is delayed. Each year, 258,000 people die from sepsis in the U.S. As many as $80 \%$ of sepsis deaths could be prevented with rapid diagnosis and treatment (Sepsis Alliance, 2016). According to the CDC, when sepsis is quickly recognized and treated, lives are saved. Healthcare providers are the critical link to preventing, recognizing, and treating sepsis (U.S. Department of Health and Human Services, 2016).

\section{Problem Statement}

The Academic Medical Center of interest does not have an existing process for screening and initiating treatment for patients diagnosed with sepsis prior to their transfer from a referring facility. At present, incoming patients are accepted by Throughput RNs in the transfer unit after 
a series of questions are answered from outlying facility personnel, but there is not a sepsis screen being utilized. The Academic Medical Center has transferred a total of 24,766 patients from outside healthcare facilities from January 1, 2014 to April 30, 2017. These patient transfers include a total of 2,147 (8.6\%) patients that were diagnosed with sepsis present on arrival when analyzed retrospectively. The early identification and treatment of these patients with sepsis may have been enhanced with the implementation of a sepsis screening process. The implementation a sepsis screening process in the transfer unit provides opportunities to improve patient care and patient outcomes related to sepsis care.

\section{Purpose of the Project}

The purpose of the project is to identify patients with sepsis earlier with the goal improving the outcomes of patients received as transfers from outside facilities. Early screening of the patients and best practice implementation within the first hour of sepsis presentation is critical to improving patient outcomes (Sepsis Alliance, 2016). The use of a sepsis screening process by the Throughput RNs at transfer unit of an Academic Medical Center will help achieve the purpose. This project seeks to improve the ability of the transfer unit to screen patients, improve early recognition and evaluation of best practices, and provide a connection with a provider for care consultation. These improvements will allow appropriate and timely care prior to patient transfer during the critical first hour of recognition.

\section{Significance of the Proposed Project}

This potential significance of this project is to improve patient outcomes including mortality, length of stay, and the assignment of patients to the appropriate level of care through early recognition of sepsis and the implementation of best practices. The use of a screening process to identify abnormal patient variables including elevated serum lactate, decreased blood 
pressure, elevated respiratory rate, and altered mental status can identify an increased likelihood of sepsis. Thus, with this early recognition care providers can intervene earlier and subsequently improve patient outcomes.

\section{Literature Review and Synthesis}

Two separate literature searches were conducted for the completion of this literature review. The first search utilized the following databases, CINAHL, MEDLINE, Academic Search Complete, and Healthsource: Nursing and Academic Edition. Search keywords included sepsis and clinical protocols as subject terms. This search resulted in 493 studies. To be including in this review the paper had to address the following: timeliness of the intervention, intervention included sepsis protocol or bundle, new onset of sepsis, peer-reviewed, English language, and adults. Papers were excluded if: intervention did not include a full sepsis bundle or protocol and disease specific related sepsis treatment. This resulted in a total of 42 paper to be reviewed.

A second review was completed because topics known to the author, such as mortality and patient outcomes, were not found in the first review. Using the same search criteria, the search keywords of sepsis protocols and mortality were used. This search resulted in 1283 papers. After applying the same inclusion and exclusion criteria and the removal of duplicates, 10 additional papers were included.

Thus, the total number of papers in the review was 52. After a review of these papers, three major themes emerged including; the issue of sepsis in hospitals, the impact of sepsis screening on recognition of sepsis and the implementation of best practices, and evidence based practices for sepsis care. 


\section{Issue of Sepsis in Hospitals}

The diagnosis and management of patients with sepsis is an important consideration for healthcare organizations. Sepsis is a complication caused by the body's overwhelming and lifethreatening response to infection, which can lead to tissue damage, organ failure, and death (CDC, 2016). Sepsis is difficult to predict, diagnose, and treat. Patients who develop sepsis have an increased risk of complications and death and face higher healthcare costs and longer treatment. From 1999-2014, the CDC found that a total of 2,470,666 decedents $(6 \%$ of all deaths) had sepsis listed among the causes of death (CDC, 2016). Many healthcare organizations have acted to improve survival rates and standardize sepsis care. However, sepsis continues to burden patient populations and continued efforts to improve healthcare organization's ability to care for these patients is necessary.

\section{Impact of Sepsis Screening on Recognition of Sepsis and Implementation of Best Practices}

The literature in this review revealed mortality rates of healthcare organization between $35.1 \%$ and $61.1 \%$ in sepsis patients prior to implementing a sepsis screening and treatment process. Following the implementation of sepsis processes each organization observed decreases in mortality. One retrospective cohort study found a decreased mortality from $43.8 \%$ to $18.2 \%$ (Trzeciak et al., 2006). Another study found decrease in mortality rates from $29.7 \%$ to $21.1 \%$ (Jones et al., 2015). A third study found a decreased mortality rate from $39.5 \%$ to $20.8 \%$ (Ngyuyen et al., 2016).

This review of literature found that many healthcare organizations were able to improve the ability to recognize sepsis in early onset with screening tools, thus improve the efficiency of best practice intervention delivery. Twelve studies in the literature review observed statistically 
significant decreases in the length of time for care providers to recognize sepsis via sepsis screening tools (Bruce et al., 2015; Dellinger et al., 2008; Focht et al., 2009; Gaieski et al., 2010; Miguel-Yanes, Andueza-Lillo, González-Ramallo, Pastor, \& Muñoz, 2006; Hayden et al., 2016; Patel et al., 2010; Puskarich et al., 2011; Tromp et al., 2010; Trzeciak et al., 2006; Westfall et al., 2011; Yealy et al., 2014). Each study that observed an increase in recognition also reported a statistically significant decrease in the amount of time to delivery best practices interventions including fluid boluses, antibiotic administration, serum lactate level draws, and blood culture draws(Bruce et al., 2015; Dellinger et al., 2008; Focht et al., 2009; Gaieski et al., 2010; MiguelYanes et al., 2006; Hayden et al., 2016; Patel et al., 2010; Puskarich et al., 2011; Tromp et al., 2010; Trzeciak et al., 2006; Westfall et al., 2011; Yealy et al., 2014).

One study observed the time to antibiotics for patients with severe sepsis and septic shock was significantly reduced in the post-BPA cohort from 61.5 minutes to 29.5 minutes. That same study observed an improved time to receive antibiotics within 60 minutes from $48.6 \%$ to $76.7 \%$ (Narayanan et al., 2005). A study witnessed improvements in overall time to cultures, first dose of antibiotics, and transfers out of the ED to the ICU due to the initiation of the bundle (Patel, Roderman, Gehring, Saad, \& Bartek, 2010). Another study observed the median time to initial antibiotic administration was reduced significantly, by 27 minutes (Bruce et al., 2015). An international study found that the mean time elapsed between the identification of the first signs of sepsis risk and the detection of sepsis was longer in phase I than in phase II (34 vs 11 hours; P $<.001)$ (Westfall et al., 2011). The time to antibiotics for another study revealed the mean time to bolus was 31 minutes less in the post implementation group at 51 vs 82 minutes (Geoffrey et al., 2016). 
Therefore, literature suggests that screening for sepsis provides an opportunity for early implementation of best practices for sepsis management. These best practices include: fluid resuscitation, antibiotics delivery, blood culture draws, and serum lactate draws.

\section{Evidence Based Practices for Sepsis Care}

Bundles and protocols.

The standard for the management of sepsis has typically utilized sepsis bundle or protocols. A care bundle or protocol is a selected set of care interventions that are designated for implementation when a clinical criterion threshold is met. The adoption of "sepsis bundles" or "sepsis protocols" that standardize best practice interventions have shown significant improvements in patient care delivery. The implementations of care bundles and protocols have been the foundation of sepsis treatment since the initial Surviving Sepsis Campaign-evidenced based guidelines introduction in 2004 (Dellinger et al., 2004). The guidelines have continued to progress in the subsequent reviews of sepsis care guidelines until the most recent evaluation in 2016 (Dellinger et al., 2008; Levy MM et al., 2010; Dellinger et al., 2013; Levy MM et al., 2015; Rhodes et al., 2015; Rhodes et al., 2017).

In the 2016 Surviving Sepsis Campaign, the evidence for each individual bundle element was graded and evaluated for the level of evidence to support its implementation. The grades and recommendation included, lactate level as a weak recommendation with a low quality of evidence, the obtaining of blood cultures prior to administration of antibiotics as a best practice statement, the administer broad-spectrum antibiotics as a strong recommendation with a moderate quality of evidence, the rapidly administration of $30 \mathrm{ml} / \mathrm{kg}$ crystalloid for hypotension or lactate $\geq 4 \mathrm{mmol} / \mathrm{L}$ as a strong recommendation with a low quality of evidence, and the application vasopressors if patient is hypotensive during or after fluid resuscitation to maintain 
$\mathrm{MAP} \geq 65 \mathrm{~mm} \mathrm{Hg}$ as a strong recommendation with a moderate quality of evidence (Rhodes et al., 2017).

Following the evaluation of evidence, recommendations were made by the Surviving Sepsis Committee for the continued use of the following care bundles for the treatment of sepsis within the first hours of treatment: measure lactate level and re-measure if initial lactate is $>2$ $\mathrm{mmol} / \mathrm{L}$; obtain blood cultures prior to administration of antibiotics; administer broad-spectrum antibiotics; rapidly administer $30 \mathrm{ml} / \mathrm{kg}$ crystalloid for hypotension or lactate $\geq 4 \mathrm{mmol} / \mathrm{L}$; and apply vasopressors if patient is hypotensive during or after fluid resuscitation to maintain $\mathrm{MAP} \geq 65 \mathrm{~mm} \mathrm{Hg}$. Although identified as a weak intervention in the literature, serum lactate was included because length of time since patient presented at outside facility to receiving facility can vary, thus some patients may have more advanced sepsis making serum lactate level an appropriate indicator.

\section{SIRS criteria.}

The American College of Chest Physicians/Society of Critical Care Medicine established the SIRS (systemic inflammatory response syndrome) criteria in a 1991 during a consensus conference when tasked with developing clinical parameters for the early identification of sepsis. The SIRS criteria identified four clinical variables to be used for the evaluation of sepsis including: (1) a body temperature greater than $38^{\circ} \mathrm{C}$ or less than $36^{\circ} \mathrm{C}$; (2) a heart rate greater than 90 beats per minute; (3) tachypnea, manifested by a respiratory rate greater than 20 breaths per minute, or hyperventilation, as indicated by a $\mathrm{PaCO}_{2}$ of less than $32 \mathrm{~mm} \mathrm{Hg}$; and (4) an alteration in the white blood cell count, such as a count greater than $12,000 / \mathrm{cu} \mathrm{mm}$, a count less than 4,000/cu mm, or the presence of more than 10 percent immature neutrophils ("bands") (Bone et al, 1992). This criterion has been the standard definition for defining sepsis since this 
consensus conference. However, the AMA (American Medical Association) reported in 2016 that the current standard of SIRS criteria is unanimously considered to be unhelpful. The AMA reported that changes in white blood cell count, temperature, and heart rate reflect inflammation, the host response to "danger" in the form of infection or other insults. The SIRS criteria do not necessarily indicate a dysregulated, life-threatening response. SIRS criteria are present in many hospitalized patients, including those who never develop infection and never incur adverse outcomes (American Medical Association. 2016).

\section{QSOFA and the development of screening tools.}

The use of sepsis screening tools for early identification of sepsis has been critical to the improvement of patient care and patient outcomes. With no validated criterion standard diagnostic testing to confirm a diagnosis of sepsis, continual efforts have been made to identify strategies to predict to sepsis in the early onset. Screening tools for sepsis are imperative to properly recognize sepsis in the clinical setting and the delivery of timely care.

The Third International Consensus Definitions for Sepsis and Septic Shock (Sepsis-3) determined that new criteria for sepsis recognition was useful for the early and accurate detection of sepsis. During the task force it was determined that qSOFA could be a useful clinical tool, especially to physicians and other practitioners working outside the ICU (and perhaps even outside the hospital, given that qSOFA relies only on clinical examination findings), to promptly identify infected patients likely to fare poorly. Also, that this simple bedside score may be particularly relevant in resource-poor settings in which laboratory data are not readily available, and when the literature about sepsis epidemiology is sparse. The qSOFA score consists of three clinical variables including altered mental status, a systolic blood pressure of $100 \mathrm{~mm} \mathrm{Hg}$ or less, 
and a respiratory rate of $22 / \mathrm{min}$ or greater. The patient is considered as a high likelihood for sepsis when two of three clinical variables are present (American Medical Association, 2017).

\section{Synthesis}

This literature review supports the pursuit of integrating a sepsis screening process using nurses within the MARS transfer line by utilizing the American Medical Association consensus definition for sepsis and the recommended qSOFA model for sepsis screening (American Medical Association, 2016). The recommendation made by the American Medical Association to utilize the qSOFA screening for the early identifications of sepsis was determined to be the most useful screening tool for the transfer center. The simplicity of the screening and the elimination of laboratory tests when compared to SIRS criteria made it more functional for the Throughput RNs to complete a quick and easy assessment of transferring patients. With a varying amount of information available during the transfer process, this simplicity and lack of need for laboratory values is an important consideration.

The incorporation of a structured screening tool and a set of pre-determined best practice interventions can play an important role in the early recognition of sepsis, timely delivery of best practice interventions, and improvements in patient outcomes. Careful considerations regarding the structure of the tools and the protocol design can influence patient outcomes. Systematic evaluation of the implementation and evaluation of screening protocols is necessary to assess the impact screening may have on patient outcomes. This literature review suggests that the priority best practice interventions to incorporate in the sepsis screening process are serum lactate level draws, blood culture draws, fluid resuscitation, vasopressor administration, and antibiotic administration. 


\section{Theoretical Framework.}

The theoretical framework utilized for this project is the Deming Cycle or the Plan Do Study Act (PDSA) model. This framework includes four major steps and involves a cycle of continual improvement and evaluation. The first step of this framework is the Plan step. The Plan step involves identifying a goal or purpose, formulating a theory, defining success metrics, and putting a plan into action. The second Do step is when the components of the plan are implemented. The Study step is where outcomes are monitored to test the validity of the plan for signs of progress and success or deficits and areas for improvement. The Act step closes the cycle by integrating the learning generated by the entire process, which can be used to adjust the goal, or change models (The Deming Institute, 2016).

\section{Project}

\section{Description and Design}

The project involves the implementation of a screening process and a provider consultation to guide care for sepsis patients prior to transferring to an Academic Medical Center. The screening process was implemented through the Medical Access Referral System (MARS) telephone line, which serves as the main hub for all transfer requests coming into the Academic Medical Center from outside facilities. The MARS transfer line is staffed at all times by Throughput Nurses. These Throughput Nurses are Registered Nurses responsible for triaging and transferring all patients to the Academic Medical Center. The Throughput Nurse will screen all adult patients referred to the MARS transfer from all referring facilities.

The screening utilizes a Quick Sequential [Sepsis-related] Organ Failure Assessment (qSOFA) score and a serum lactate level as an indicator of sepsis. The qSOFA score has three 
clinical variables including altered mental status, a systolic blood pressure of $100 \mathrm{~mm} \mathrm{Hg}$ or less, and a respiratory rate of 22/min or greater (American Medical Association, 2017). The patient is considered as a high likelihood for sepsis with two of three clinical variables for the qSOFA score and/or an elevation of a serum lactate $\geq 4.0 \mathrm{mmol}(36 \mathrm{mg} / \mathrm{dl})$.

Following the screening process, the Throughput Nurse initiates the care consultation when a qSOFA score of two or greater exists and/or an elevation of a serum lactate $\geq 4.0$ $\mathrm{mmol}(36 \mathrm{mg} / \mathrm{dl})$ exists. If the patient does not score a two or greater and has a serum lactate level $<4.0 \mathrm{mmol}(36 \mathrm{mg} / \mathrm{dl})$, the consultation will not occur and the standard pathways for patient acceptance and admission will be completed. The care consultation process will involve direct communication between the referring provider and a designated member of the medical team at the Academic Medical Center via the MARS transfer phone line. Once the consultation is completed, the patient will be accepted to an appropriate service and wait for bed placement and patient transportation. See Appendix A for Sepsis Screening Process Algorithm

\section{Pilot Study}

A pilot study will be conducted during the first month of implementation using the PDSA theoretical framework for evaluating the project processes. During this period one on one interviews, meetings with Throughput RNs and consulting MDs, and a Throughput RN survey will be completed to evaluate acceptability, practicality, and limited efficacy. Based on pilot study changes will be made to the project (NIH, 2009).

\section{Fit of Theoretical Framework to Project}

The chosen framework works well for this planned project as it provides a solid groundwork for a quality improvement project in a healthcare organization. It analyzes each 
stage of a change project as it would naturally occur and allows for evaluation of outcomes and reentrance into the cycle to perfect the system change. (See Appendix B)

\section{Feasibility Analysis}

The planned project intervention is driven by current clinical guidelines repurposed for patient transfers via the MARS transfer line. The current screening methods and consultation process is an approved organizational process. (See Appendix A) The functional requirements involve a software system adaptation that will integrate the sepsis screening alert into MARS transfer process. There are no confidentiality, privacy, or security issues with the change project. The proposed change is feasible within known technical constraints and current staff skills. The change requires no additional demands on human resources. The change will affect the amount of time for each MARS transfer call by an estimated 2 to 10 minutes.

\section{Project resources.}

The total costs of the project will be covered by organizational contributions. The hourly wage contribution of the organization constitutes $98 \%$ of the of the total project costs. The hourly wages are required for educational sessions and additional time spent during transfer calls. The hourly wages reflect current full time employees in their current roles within the organization. No additional personnel will be required outside of their current role for the implementation of the project. The participation of one House Supervisor will be voluntary as they are a key contributor to the planned project. The House Supervisor's role is to work directly with the Throughput Nurses to oversee patient transfers and manage bed placement. See the attached capstone budget plan and justification (See Appendix D). 


\section{Organizational and project needs assessment.}

The planned project utilizes current MARS line throughput nurses and on call internal physicians working within their current roles. No additional staff will be required for the implementation or continuation of the project. The screening process will require additional time per MARS transfer call but it require no addition organizational workflow changes to accommodate the additional time. The training will be completed by the MARS supervisor and the principle project champion and will require no additional training personnel. The Throughput nurse training sessions will be completed during their normal working hours and will require no additional time for completion. Training for the sepsis expert consultation will occur during work hours and will require no additional resources. (See Appendix C) The planned project reinforces and expands the existing sepsis screening tools and sepsis protocols for care. No additional needs are identified to implement these aspects of the project.

A strengths weaknesses opportunities and threats (SWOT) analysis was performed for this project and indicated the strengths of this project to be interdisciplinary support for change, support by current MARS line employees, limited financial investment necessary for change, sepsis experts and clinical expertise within the organization, and strong leadership support for change. The weaknesses for the project were identified as inconsistent organizational use of the current sepsis BPA alert and sepsis protocol orders, and the potential resistance of internal care providers. The opportunities that were identified included the organization's positioning as the leader of a growing health system in its state, the organization serving as the main destination for tertiary care transfers in the state, and the organization's strong financial positioning. The threats to the project included external physician's resistance to change, and the inconsistencies of external physician's preferences on the delivery of care. 


\section{Congruence to the strategic plan of the organization.}

WVU Medicine's mission is to improve the health of West Virginians and all we serve through excellence in patient care, research, and education. (WVU Medicine, 2017) The planned project's goals of improving the transfer process for sepsis patients and improving patient outcomes aligns well with WVU Medicine's mission statement. This project has the potential to reach a large population of West Virginians through collaborative patient care strategies, education of healthcare providers, and the research of evidence based practice application within the organization's health system.

The planned project aligns well with the vision of the organization. The project will seek to expand the delivery of expert evidence based care throughout the organization's health system. It seeks to unify a culture of care delivery to its highest level and transform the delivery of care so that its population can receive the right care in the right place at the right time. WVU Medicine's Vision is to:

Transform lives and eliminate health disparities through a nationally recognized patientcentered system of care that includes: An expanded regional healthcare delivery system, consistent, integrated patient care recognized for delivering the right care in the right place at the right time at all sites, development of new approaches to improve healthcare, including team-based models of care, expanding WVU clinical and translational research, educational programs throughout the network recognized for training uniquely qualified healthcare team members and leaders, and a culture of performance and excellence throughout the network (WVU Medicine, 2017).

\section{Evidence of key site support.}


The principle stakeholders for the planned project are the MARS transfer line leadership team. This MARS leadership team, including the Director and Manager, has offered their support for the implementation of the project. Other key stakeholders that have offered support for the project include the organization's Chief Operating Officer, members of the sepsis committee, the Director of the Center for Quality Outcomes, and the Chief Quality Officer.

\section{Project Timeline}

The planned phases of the project will begin with the Institutional Review Board process to be completed by December 15, 2017. The education sessions for both the Throughput RNs and sepsis consult experts will be completed by January 15, 2018. The planned project's intervention implementation will take place on February 1, 2018 and will be monitored for three months through April 30, 2018. An audit and chart review of retrospective data for transferring will be completed by March 1, 2018 to determine effectiveness and sustainability. The final presentation of the project, including an overview and a project analysis will be conducted by December 1, 2018. (See Appendix E)

\section{Measurable Project Aims and Objectives}

The proposed project has two main aims. These aims are, Aim 1: to evaluate the usefulness of a new sepsis screening process and Aim 2: to evaluate the impact of the new sepsis screening process on patient outcomes. See Table 1.

Aim 1 has three main objectives. Objective 1: the screening accurately identifies those patients with sepsis present on arrival; AEB: A: the total number of positive screens with a diagnosis of sepsis present on arrival(true positives), B: the total number of negative screens with a diagnosis of sepsis present on arrival(false negatives), $\mathrm{C}$ : the total number of positive screens 
without a diagnosis of sepsis present on arrival(false positives), and D: the total number of negative screens without a diagnosis of sepsis(true negatives).

For objective 1, sensitivity and specificity will be calculated using the true positive, false negative, true negative, and false positive results. Sensitivity is calculated to measure the proportion of actual positives that are correctly identified as such (true positives/true positives + false negatives). Specificity is calculated to measure the proportion of actual negatives that are correctly identified as such (true negatives/true negatives + false positives).

Objective 2: Increase the number of patients receiving Best Practices for sepsis management, AEB: An increase the number of Best Practices implemented from initial screening to arrival at WVU Medicine- Ruby Memorial. Objective 3: Implementation of screening will be timely and efficient, AEB: A: the number of minutes for throughput nurse to screen for sepsis and evaluate Best Practices and B: the number of minutes for screening to provider/transfer connection.

Aim 2 has one main objective. Objective 1: implementation of sepsis screening process will improve patient outcomes, AEB: A: decreased length of stay in the post-implementation period compared to the pre-implementation period, B: decreased mortality rate in the postimplementation period compared to the pre-implementation period, and C: decreased escalation of care prior to transfer or within the first 24 hours of admission to WVU Medicine Ruby Memorial. 
Table 1: Measurable Project Aims and Objectives: Evaluation Plan

\begin{tabular}{|c|c|c|c|c|c|}
\hline Aim & Objective/Criteria, AEB & $\begin{array}{l}\text { Target } \\
\text { Population }\end{array}$ & What Data to Collect & $\begin{array}{l}\text { Collection } \\
\text { Methods }\end{array}$ & Data Analysis \\
\hline $\begin{array}{l}\text { Aim1: } \\
\text { Evaluate } \\
\text { the } \\
\text { usefulness } \\
\text { of a new } \\
\text { sepsis } \\
\text { screening } \\
\text { process }\end{array}$ & $\begin{array}{l}\text { 1. Screening accurately identifies } \\
\text { those patients with sepsis present } \\
\text { on arrival, AEB: } \\
\text { A. Total number of positive } \\
\text { screens with a diagnosis } \\
\text { of sepsis present on } \\
\text { arrival (True positives) } \\
\text { B. Total number of positive } \\
\text { screens without a } \\
\text { diagnosis of sepsis } \\
\text { present on arrival (False } \\
\text { positives) } \\
\text { C. Total number of negative } \\
\text { screens with a diagnosis } \\
\text { of sepsis present on } \\
\text { arrival (False negatives) } \\
\text { D. Total number of negative } \\
\text { screens without a } \\
\text { diagnosis of sepsis (true } \\
\text { negatives) }\end{array}$ & $\begin{array}{l}\text { Nurses } \\
\text { Consultants } \\
\text { Outside } \\
\text { facilities } \\
\text { Patients } \\
\text { Medical } \\
\text { Records }\end{array}$ & $\begin{array}{l}\text { Objective 1. qSOFA } \\
\text { scores and/or Serum } \\
\text { Lactate levels } \\
\text { compared to sepsis } \\
\text { diagnosis POA }\end{array}$ & $\begin{array}{l}\text { Chart } \\
\text { Review } \\
\text { Call- Miner } \\
\text { transcripts }\end{array}$ & $\begin{array}{l}\text { Objective 1. Quantitative } \\
\text { analysis using descriptive } \\
\text { statistics, frequencies, and } \\
\text { percentage calculations } \\
\text { Sensitivity and specificity } \\
\text { calculations using standard } \\
\text { formulas. }\end{array}$ \\
\hline
\end{tabular}




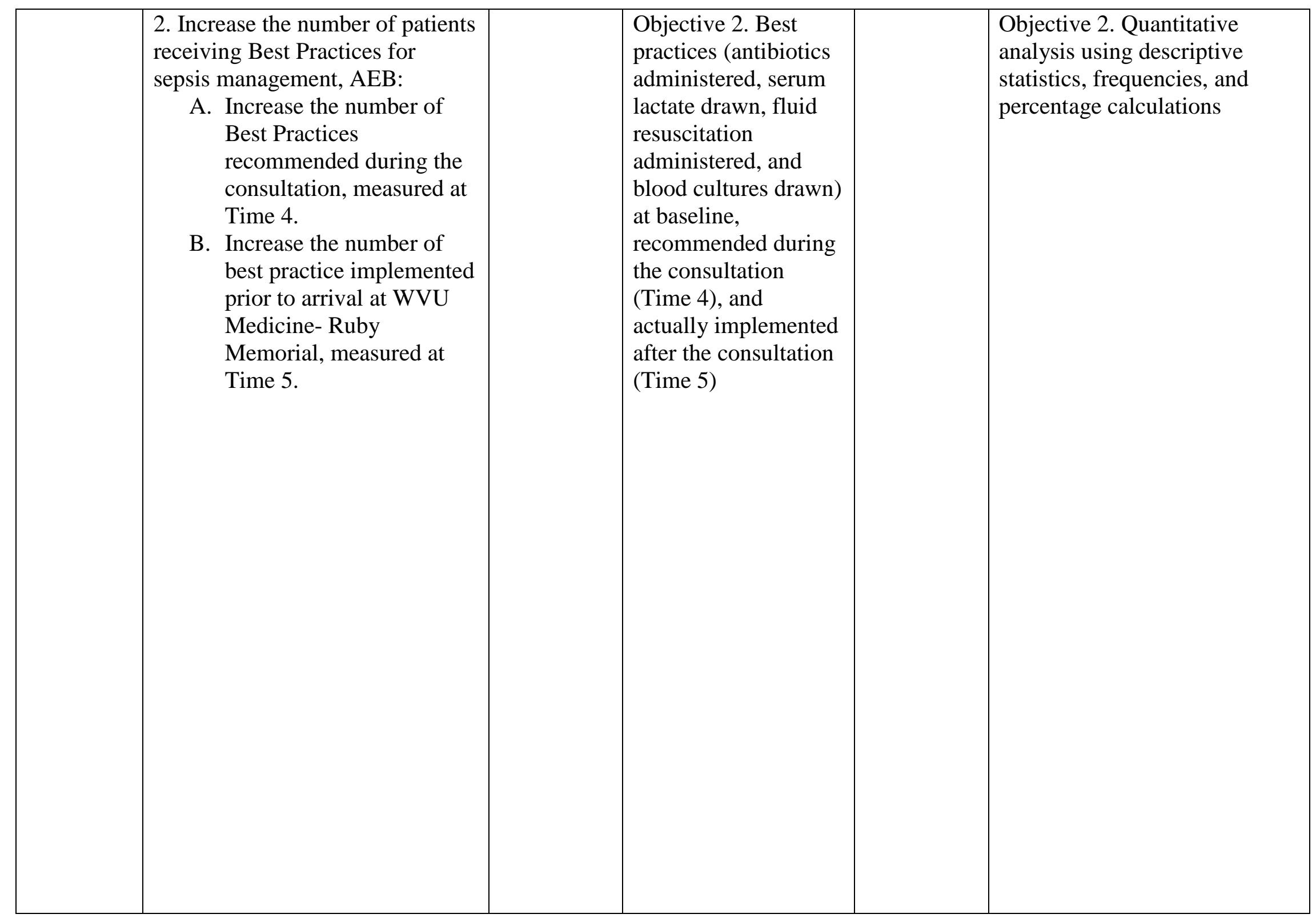




\begin{tabular}{|c|c|c|c|c|c|}
\hline & $\begin{array}{l}\text { 3. Implementation of screening } \\
\text { will be timely and efficient, AEB: } \\
\text { A. Number of minutes for } \\
\text { throughput nurse to } \\
\text { screen for sepsis and } \\
\text { evaluate Best Practices } \\
\text { (Time 1-Time 2) } \\
\text { B. Number of minutes for } \\
\text { screening to } \\
\text { provider/transfer } \\
\text { connection (Time 2- Time } \\
\text { 3) }\end{array}$ & & $\begin{array}{l}\text { Objective } 3 \text {. Data } \\
\text { collected at project } \\
\text { time points: Time } 1 \text {, } \\
\text { Time } 2 \text {, and Time } 3 \text {. }\end{array}$ & & $\begin{array}{l}\text { Objective } 3 \text {. Quantitative } \\
\text { analysis using descriptive } \\
\text { statistics including frequency } \\
\text { and central tendency to } \\
\text { describe interval data. }\end{array}$ \\
\hline $\begin{array}{l}\text { Aim 2: } \\
\text { Evaluate } \\
\text { the impact } \\
\text { of the new } \\
\text { sepsis } \\
\text { screening } \\
\text { process on } \\
\text { patient } \\
\text { outcomes }\end{array}$ & $\begin{array}{l}\text { Objective } 1 . \text { Implementation of } \\
\text { sepsis screening process will } \\
\text { improve patient outcomes, AEB: } \\
\text { A. Decreased length of stay } \\
\text { in the post- } \\
\text { implementation period } \\
\text { compared to the pre- } \\
\text { implementation period } \\
\text { B. Decreased mortality rate } \\
\text { in the post- } \\
\text { implementation period } \\
\text { compared to the pre- } \\
\text { implementation period } \\
\text { C. Decreased escalation of } \\
\text { care prior to transfer or } \\
\text { within the first } 24 \text { hours } \\
\text { of admission to WVU } \\
\text { Medicine Ruby } \\
\text { Memorial. }\end{array}$ & $\begin{array}{l}\text { Patients } \\
\text { pre/post- } \\
\text { process } \\
\text { implementa } \\
\text { tion }\end{array}$ & $\begin{array}{l}\text { Objective } 1 . \text { Length } \\
\text { of stay, mortality } \\
\text { rate, escalation of } \\
\text { care. }\end{array}$ & $\begin{array}{l}\text { Chart } \\
\text { review }\end{array}$ & $\begin{array}{l}\text { Objective 1A. Quantitative } \\
\text { analysis using descriptive } \\
\text { statistics including frequency } \\
\text { and central tendency } \\
\text { comparing pre- } \\
\text { implementation interval data } \\
\text { (length of stay) to post- } \\
\text { implementation interval data } \\
\text { (length of stay). t-test to } \\
\text { determine statistical difference } \\
\text { between the pre/ post data on } \\
\text { continuous variable of LOS. } \\
\text { Chi Square Goodness of fit test } \\
\text { to compare differences } \\
\text { between pre/post data on } \\
\text { categorical variables. } \\
\text { Objective 1B. Quantitative } \\
\text { analysis using descriptive } \\
\text { statistics including frequency }\end{array}$ \\
\hline
\end{tabular}




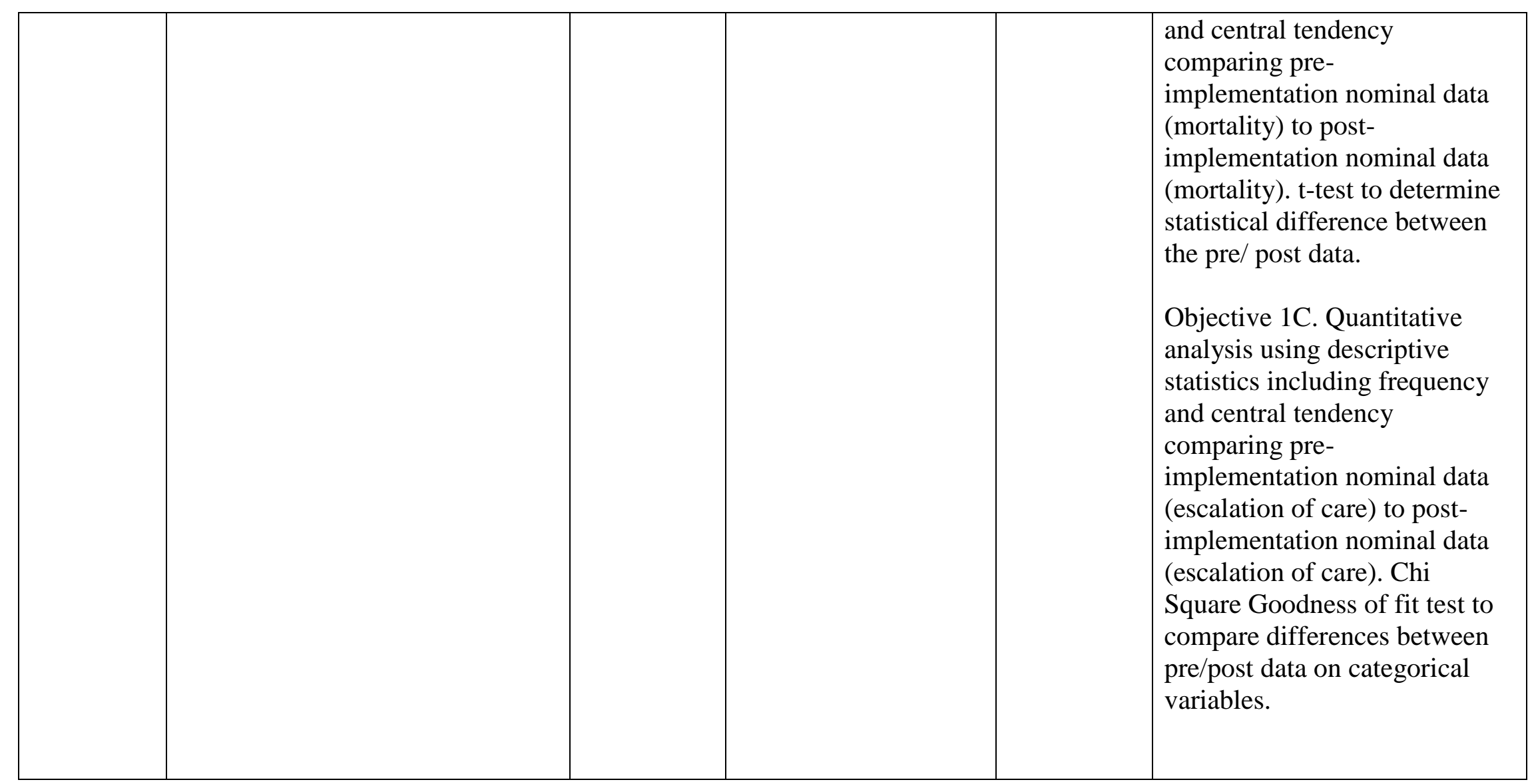




\section{Results}

1270 patients were screened during the study period. The sample ages ranged from 18 to 99, including $85(6.69 \%)$ age $18-29,82(6.46 \%)$ age $30-39,130(10.24 \%)$ age $40-49,233(18.35 \%)$ age $50-59,295(23.23 \%)$ age $60-69,289(22.76 \%)$ age $70-79,139(10.94 \%)$ age $80-89$, and $17(1.34 \%)$ age $90-99$. The majority of the screened patients were white $(98.19 \%), 1.57 \%$ were black, less than $1 \%$ were Asian, less than $1 \%$ were Hispanic, and less than $1 \%$ reported than ethnicity as other. 191(15.04\%) were commercially insured, 306(24.09\%) were Medicaid, 757(59.61\%) were Medicare, 2(0.16\%) were insured through workers compensation, and $14(1.10 \%)$ were self-pay or uninsured. Screened patients were from 67 different facilities in 49 counties located throughout West Virginia, Kentucky, Virginia, Pennsylvania, and Ohio. Refer to Table 1 for a more detailed description of the demographics. See figure 1.

Of the 1270 patients screened, 225 patients were confirmed with sepsis upon arrival to the academic medical center. The majority of the screened patients were white $(97.78 \% \%)$, $1.78 \% \%$ were black, less than $1 \%$ were Hispanic, are no patients reported as an ethnicity of Asian or Other. Gender distribution of the patients was similar, 55.56\% of the sample were male and $44.44 \%$ were female. The patients with the diagnosis of sepsis present on arrival ages ranged from 18 to 98 , including $19(8.44 \%)$ age $18-29,15(6.67 \%)$ age $30-39,24(10.67 \%)$ age $40-49$, $39(17.33 \%)$ age $50-59,64(28.44 \%)$ age $60-69,45(20.00 \%)$ age $70-79,17(7.56 \%)$ age $80-89$, and $2(0.89 \%)$ age $90-99.73 .33 \%$ of the patients were $>$ the age of 50 with the largest number of patients between the ages of 60-69. 28(12.44\%) were commercially insured, $72(32.00 \%)$ were Medicaid, 124(55.11\%) were Medicare, 0 were insured through workers compensation, and $1(0.44 \%)$ were self-pay or uninsured. See Table 2. 
Figure 1

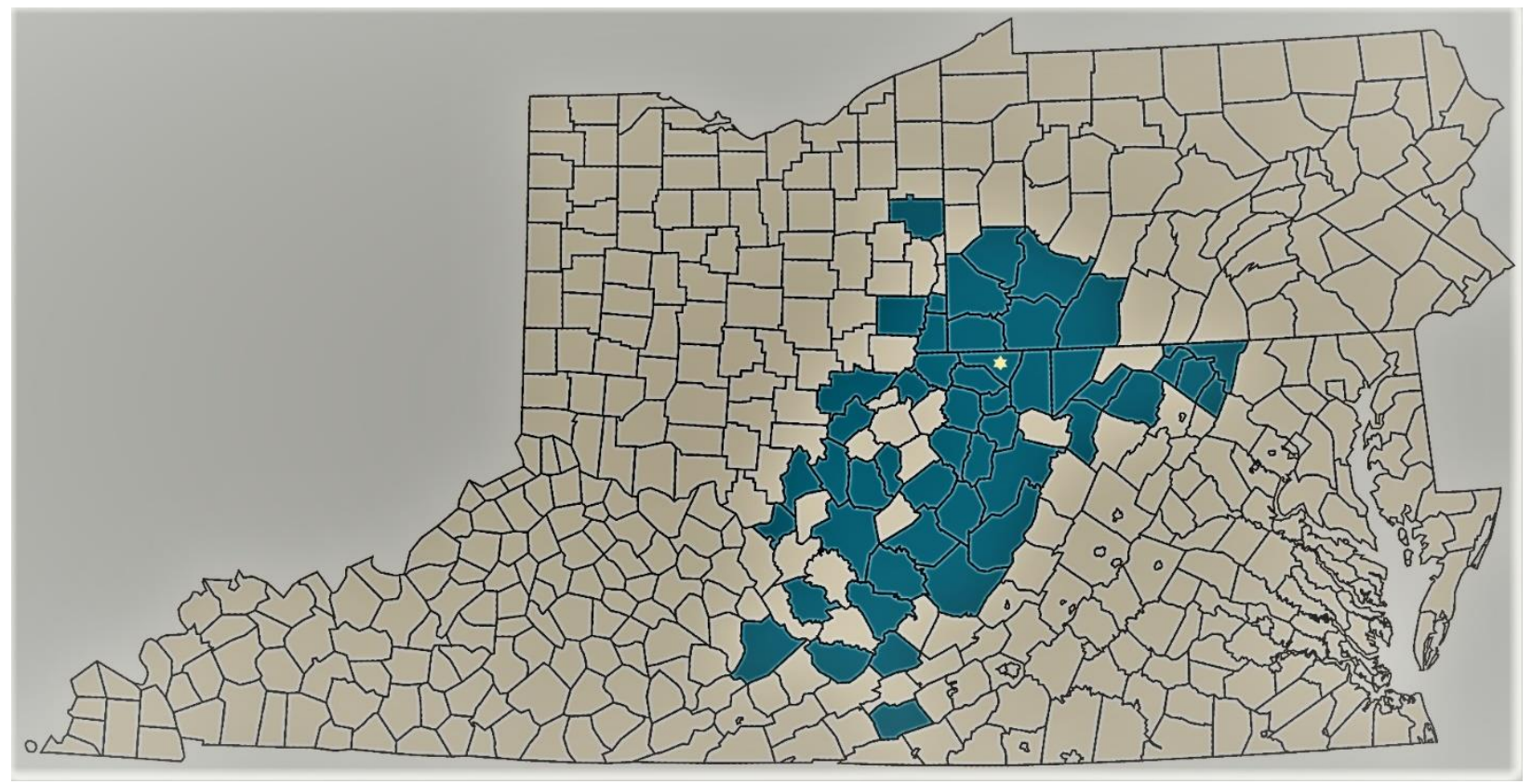

Table 2

\begin{tabular}{|l|l|r|r|}
\hline \multirow{5}{*}{ Group Characteristic } & Category & Total Screened(1270) & Total Sepsis POA(225) \\
\hline \multirow{5}{*}{ Ethnicity } & White & $1246(98.11 \%)$ & $220(97.78 \%)$ \\
\cline { 2 - 4 } & Black & $20(1.57 \%)$ & $4(1.78 \%)$ \\
\cline { 2 - 4 } & Asian & $2(0.16 \%)$ & $0(0.00 \%)$ \\
\cline { 2 - 4 } & Hispanic & $1(0.08 \%)$ & $1(0.44 \%$ \\
\cline { 2 - 4 } & Other & $1(0.08 \%)$ & $0(0.00 \%$ \\
\hline \multirow{5}{*}{ Gender } & Male & $668(52.60 \%)$ & $125(55.56 \%)$ \\
\cline { 2 - 4 } & Female & $602(47.40 \%)$ & $100(44.44 \%)$ \\
\hline & $18-29$ & $85(6.69 \%)$ & $19(8.44 \%)$ \\
\cline { 2 - 4 } & $30-39$ & $82(6.46 \%)$ & $15(6.67 \%)$ \\
\cline { 2 - 4 } & $40-49$ & $130(10.24 \%)$ & $24(10.67 \%)$ \\
\cline { 2 - 4 } & $50-59$ & $233(18.35 \%)$ & $39(17.33 \%)$ \\
\cline { 2 - 4 } & $60-69$ & $295(23.23 \%)$ & $64(28.44 \%)$ \\
\cline { 2 - 4 } & $70-79$ & $289(22.76 \%)$ & $45(20.00 \%)$ \\
\cline { 2 - 4 } & $80-89$ & $139(10.94 \%)$ & $17(7.56 \%)$ \\
\cline { 2 - 4 } & $90-99$ & $17(1.34 \%)$ & $2(0.89 \%)$ \\
\hline & Commercially & $191(15.04 \%)$ & $28(12.44 \%)$ \\
\hline & insured & $306(24.09 \%)$ & $72(32.00 \%)$ \\
\cline { 2 - 4 } & Medicaid & & \\
\hline
\end{tabular}




\begin{tabular}{|l|l|r|r|}
\hline Payor Source & Medicare & $757(59.61 \%)$ & $124(55.11 \%)$ \\
\cline { 2 - 4 } & $\begin{array}{l}\text { Workers } \\
\text { compensation }\end{array}$ & $2(0.16 \%)$ & $0(0.00 \%)$ \\
\cline { 2 - 4 } & $\begin{array}{l}\text { Self-pay or } \\
\text { uninsured }\end{array}$ & $14(1.10 \%)$ & $1(0.44 \%)$ \\
\hline
\end{tabular}

\section{Aim1: Evaluate the Usefulness of a New Sepsis Screening Process}

\section{Objective 1.}

Screening accurately identifies those patients with sepsis present on arrival, AEB: 1a. The total number of positive screens with a diagnosis of sepsis present on arrival. $1 \mathrm{~b}$. The total number of negative screens with a diagnosis of sepsis present on arrival. 1c. The total number of positive screens without a diagnosis of sepsis present on arrival. 1d. The total number of negative screens without a diagnosis of sepsis.

\section{Objectives 1 A/B.}

Out of 1270 patients screened for likelihood of sepsis, 159 screened high likelihood for having sepsis, and 1111 screened likelihood of being negative for sepsis. Of the 159 screened high likelihood, 92 had a positive diagnosis of sepsis on arrival, and 67 did not have a diagnosis of sepsis on arrival. Thus screening accurately identified $57.9 \%$ (screened positive who were actually positive/total number screened positive) of the "true positives" for a diagnosis of sepsis on arrival; however, $42.1 \%$ did not have sepsis, but screened high likelihood of having sepsis, or "false positives".

\section{Objectives 1 C/D.}

Of the 1111 screened likelihood of being negative for sepsis, there were actually 133 patients with a positive diagnosis of sepsis ("false negative") on arrival, and 978 did not have a 
diagnosis of sepsis on arrival ("true negatives"). Thus, $88 \%$ were appropriately screened as negative likelihood for sepsis and did not have a diagnosis of sepsis on arrival.

From objective 1 sensitivity and specificity were calculated. Sensitivity (also called the true positive rate) measures the proportion of actual positives that are correctly identified as such (e.g., the percentage of patients with sepsis who are correctly identified as having sepsis). Overall sensitivity was $40.89 \%$ (true positives/true positives + false negatives). Specificity (also called the true negative rate) measures the proportion of actual negatives that are correctly identified as such (e.g., the percentage of patients without sepsis who are correctly identified as not having sepsis). Overall specificity was $93.59 \%$ (true negatives/true negatives + false positives). Refer to Table 3 for a more detailed description of screening results.

\section{Table 3}

\begin{tabular}{|c|c|}
\hline Total \# Screened & 1270 \\
\hline Of those screened, \#of positive screens & 159 \\
\hline Of those screened, \#of negative screens & 1111 \\
\hline Total \# with diagnosis of sepsis POA & 225 \\
\hline Of those screened positive, \# with sepsis POA & 92 \\
\hline Of those screened negative, \# with sepsis POA & 133 \\
\hline Total \# without a diagnosis of sepsis POA & 1045 \\
\hline Of those screened positive, \# without sepsis POA & 67 \\
\hline Of those screened negative, \# without sepsis POA & 978 \\
\hline
\end{tabular}


$159(11.44 \%)$ of the 225 confirmed patient with sepsis present on arrival had positive screens. Out of that 159, $18(11 \%)$ had a qSOFA score of 2 or greater and a serum lactate level of $4.0 \mathrm{mmol} / \mathrm{l}(36 \mathrm{mg} / \mathrm{dl})$ or greater, $38(24 \%)$ patients had a serum lactate level of $4.0 \mathrm{mmol} / \mathrm{l}(36$ $\mathrm{mg} / \mathrm{dl})$ or greater alone, and $103(65 \%)$ had a qSOFA score of 2 or greater alone.

In determining whether a screen is positive or not, a patient could have a positive qSOFA score and/or an elevated Serum Lactate level. 159(11.44\%) of the 225 confirmed patient with sepsis present on arrival had positive screens; 18 had a qSOFA score of 2 or greater and a serum lactate level of $4.0 \mathrm{mmol} / 1(36 \mathrm{mg} / \mathrm{dl})$ or greater, 38 patients had a serum lactate level of $4.0 \mathrm{mmol} / 1(36 \mathrm{mg} / \mathrm{dl})$ or greater alone, and $103 \mathrm{had}$ a qSOFA score of 2 or greater alone. Refer to Table 4 for a more detailed description of the screening triggers.

\section{Table 4}

\begin{tabular}{|l|l|}
\hline Total number of positive screens & $\mathbf{1 5 9}$ \\
\hline qSOFA score $\geq 2$ and Serum lactate $\geq 4.0 \mathrm{mmol} / 1(36 \mathrm{mg} / \mathrm{dl})$ & 18 \\
\hline Serum lactate $\geq 4.0 \mathrm{mmol} / \mathrm{l}(36 \mathrm{mg} / \mathrm{dl})$ alone & 38 \\
\hline qSOFA score $\geq 2$ alone & 103 \\
\hline
\end{tabular}

\section{Objective 2 .}

Increase the number of patients receiving Best Practices for sepsis management, AEB:

2a. An increase in the number of Best Practices implemented from initial screening to arrival at the academic medical center.

\section{Number of best practices implemented prior to consultation.}


Of the 159 patient positive screens in the pre-consultation period (Time 2), 80(50.31\%) received fluid resuscitation, $113(71.7 \%)$ received antibiotics, $107(67.3 \%)$ had blood cultures drawn, and $128(80.50 \%)$ had a serum lactate level drawn. Of the 92 true positives for sepsis (determined by confirmed diagnosis of sepsis POA) in the pre-consultation period, 54 (58.70\%) were receiving fluid resuscitation, $82(89.13 \%)$ were receiving antibiotics, $68(73.91 \%)$ had blood cultures drawn, and $77(83.70 \%)$ had serum lactate drawn. Refer to Table 5.

\section{Number of best practices recommended.}

Of the 92 positive screens with confirmed sepsis POA, a total of 24 best practice recommendations were made during the consultation period, which was measured at Time 3. This data included: 9 (9.78\%) for fluid resuscitation or pressor administration, 14 (15.22\%) for antibiotic administration, and $1(1.09 \%)$ for blood culture draws. No recommendations were made during the consultation period for serum lactate level draws. Refer to Table 5.

\section{Number of best practices implemented.}

16 of the 24 total recommendations were confirmed as completed prior to arrival via chart review including, $8(8.7 \%)$ of the fluid resuscitation or pressor administration recommendations, $7(7.61 \%)$ of the antibiotic recommendations, and the $1(1.09 \%)$ blood culture draw recommendation. Refer to Table 5.

\section{Table 5}

\begin{tabular}{|l|l|}
\hline Best Practices Implemented Prior to Consultation & Positive Screens (159) \\
\hline Fluid resuscitation/ pressor & $80(50.31 \%)$ \\
\hline Antibiotics & $113(71.07 \%)$ \\
\hline Blood cultures & $107(67.30 \%)$ \\
\hline Serum Lactate & $128(80.50 \%)$ \\
\hline
\end{tabular}




\begin{tabular}{|l|l|}
\hline Best Practices Implemented Prior to Consultation & True Positives (92) \\
\hline Fluid resuscitation/ pressor & $54(58.70 \%)$ \\
\hline Antibiotics & $82(89.13 \%)$ \\
\hline Blood cultures & $68(73.91 \%)$ \\
\hline Serum Lactate & $77(83.70 \%)$ \\
\hline Number of Best Practices Recommended & True Positives (92) \\
\hline Fluid resuscitation/ pressor & $9(9.78 \%)$ \\
\hline Antibiotics & $14(15.22 \%)$ \\
\hline Blood cultures & $1(1.09 \%)$ \\
\hline Serum lactate & $0(0.00 \%)$ \\
\hline Total & 24 \\
\hline Number of Best Practices Implemented & True Positives $(92)$ \\
\hline Fluid resuscitation/ pressor & $8(8.70 \%)$ \\
\hline Antibiotics & $7(7.61 \%)$ \\
\hline Blood cultures & $1(1.09 \%)$ \\
\hline Serum lactate & $0(0.00 \%)$ \\
\hline Unable to determine via chart review & $8(8.70 \%)$ \\
\hline Total confirmed via chart review & 16 \\
\hline &
\end{tabular}

\section{Objective 3.}

Implementation of screening will be timely and efficient, AEB: $3 \mathrm{a}$. The number of minutes for throughput nurse to screen for sepsis and evaluate Best Practices (Time 1 to Time2). 3b. The number of minutes for the completion of the screening to consultation connection (Time 2 to Time 3$)$.

Of the 159 patients screening positive, times were capture for 125 patients. The mean number of minutes for throughput nurse to screen for sepsis and evaluate Best Practices was 00:02:26 $($ median $=2: 00 ;$ mode $=2: 00 ;$ range $=1: 00-11: 00)$. The mean number of minutes from screening to provider/transfer connection was 10:13 minutes $($ median $=6: 00 ;$ mode $=4: 00$; range: $1: 00-2: 11: 00)$. 
Implementation of sepsis screening process will improve patient outcomes, AEB: 2a. A decreased length of stay in the post-implementation period compared to the pre-implementation period. $2 \mathrm{~b}$. A decreased mortality rate in the post-implementation period compared to the preimplementation period. 2c. A decrease in escalation of care prior to transfer or within the first 24 hours of admission to the academic medical center.

\section{Objective 1A: LOS.}

Of the 244 patients transferred with a diagnosis of sepsis present or arrival between November 1st, 2017 and January 31st. 2018, length of stay was 12.7 days. Of the 225 patients transferred with a diagnosis of sepsis present on arrival between February 1st, 2018 and April 30th, 2018, length of stay was 14.87 days. A 2.17 day increase in length of stay was witnessed between the pre-implementation period and the post-implementation period. However, statistical analysis revealed that this difference was not significant $(\mathrm{p}=.098)$. See Appendix F describing statistical analysis.

\section{Objective 1B: Mortality.}

Of the 244 patients transferred with a diagnosis of sepsis present or arrival between November 1st, 2017 and January 31st. 2018, mortality occurred in 74(30.33\%) cases. Of the 225 patients transferred with a diagnosis of sepsis present on arrival between February 1st, 2018 and April 30th, 2018, mortality occurred in 50(22.22\%) cases. A decreased mortality rate of 8.11 percentage points was observed between the pre-implementation period and the postimplementation period. Statistical analysis revealed that there is a significant difference in mortality, $\mathrm{x} 2(1, \mathrm{n}=225)=6.48, \mathrm{p}=.01$. See Appendix F describing statistical analysis.

\section{Objective 1C: EOC.}


Of the 244 patients transferred with a diagnosis of sepsis present or arrival between November 1st, 2017 and January 31st. 2018, escalation of care occurred in 46(18.85\%) cases. Of the 225 patients transferred with a diagnosis of sepsis present on arrival between February 1st, 2018 and April 30th, 2018, escalation of care occurred in 34(15.11\%) cases. A decreased escalation of care of 3.74 percentage points was observed between the pre-implementation period and the post-implementation period. There were no significant differences between the pre-intervention and the post-intervention groups on EOC. See Appendix F describing statistical analysis.

\section{Discussion and Recommendations}

\section{Theoretical Framework}

The theoretical framework utilized for this project is the Deming Cycle or the Plan Do Study Act (PDSA) model. This framework's four major steps were operationalized throughout the implementation of this project. The first step of this framework is the Plan step. The Plan step involves identifying a goal or purpose, formulating a theory, defining success metrics, and putting a plan into action models (The Deming Institute, 2016). During the plan phase, a literature review was completed. The key organizational stakeholders were identified and recruited for implementation support. The project AIMs and objectives were developed. A sepsis steering committee was formalized and organized with a focus on sepsis treatment for patient transfers. The establishment of baseline organizational measures was completed and the formation of key measures for the project were outlined to measure the effectiveness of the process. 
The second Do step is when the components of the plan are implemented (The Deming Institute, 2016). In this step, a documentation process was built within the electronic health record system at the site of the implementation. Education sessions were completed with site providers and Throughput RNs. Meetings were conducted with the key project stakeholders. The sepsis screening process was then implemented during this step with a continued evaluation of the process steps.

The Third Study step is where outcomes are monitored to test the validity of the plan for signs of progress and success or deficits and areas for improvement (The Deming Institute, 2016). This step was utilized continually throughout the duration of the study. After 1 month of studying the intervention, the study step was utilized via a staff survey and employee interviews. The three lessons learned during the first month of study were a variance in the Serum Lactate measurement, the inability to gather a GCS consistently at some outside facilities, and a varying definition of fluid resuscitation at sending facilities. Adjustments were made based on these finding and addressed in the next act step.

The Act step closes the cycle by integrating the learning generated by the entire process, which can be used to adjust the goal, or change models. It was realized during the study phase that adjustments were needed to the processes. During this phase, adjustments to the screening process were made including Serum Lactate measurements, fluid resuscitation definitions, and altered mental status measurements. Serum Lactate for some sending facilities was found to be measured in $\mathrm{mg} / \mathrm{dL}$. Thus, the screening threshold for Serum Lactate was adjusted to $4 \mathrm{mmol} / \mathrm{L}$ or $36 \mathrm{mg} / \mathrm{dL}$ to accommodate both measurements. The inability to consistently collect a GSC from sending facilities was also realized. Thus, a transition of the screening to altered mental status from GSC was made to improve the efficiency and ability of the throughput RNs to perform the 
screening. A varying definition of fluid resuscitation at sending facilities was also recognized. An adjustment to a more detailed questioning on fluid resuscitation was made to accurately define the exact amount of fluid received at the sending facility prior to the transfer call rather than the previous binary response of yes or no. Following these adjustments, the processes were then quickly cycled back into the theoretical framework for continued study. The ability for quick rapid cycle improvements made the PDSA model idealistic for the implementation this project.

\section{Clinical Significance of Study Findings}

The implementation of the sepsis screening process had a clinically significant impact on this patient population. EOC: The 3.74 percentage points decrease in escalation of care decreased the burden of resources needed to move patients between care units. An increase in the recognition of patient's acuity level and a subsequent prioritization in bed placement allowed for patients to be assigned to beds earlier. The improved assignment of patients to the appropriate level of care also allowed the appropriate care interventions to be started immediately upon arrival to the hospital with the resources needed in place to monitor and perform care.

Mortality: The decrease in mortality of 8.11 percentage points clinical significance was related to the placement of these patients in the correct level of care, an improvements in the awareness of these septic patients by the Throughput RNs and Bed Coordinators that prioritized these patients, the provider consultations that occurred, and the increase in interventions delivered at outside facilities based on the recommendations of the providers during consultation.

Length of Stay: The 2.17 day increase in length of stay observed could be directly related to the decrease in mortality observed in the pre/post groups. Mortality and early death in patients 
transferring with sepsis are typically linked to shorter lengths of stay. Thus, the decrease in mortality could play a large role in these added days. The screening was also found to more accurately identify severe sepsis cases than the less acute sepsis cases A sub analysis of the transferring patient's severity of illness was completed to describe the sensitivity of the screening process for severe sepsis. The sub analysis revealed that the sepsis screening screened $58.26 \%$ of the severe sepsis patients accurately and only $22.78 \%$ of the lower severity sepsis patients accurately. The screenings ability to identify higher acuity cases, may have skewed the LOS findings because less of the lower acuity level cases were recognized where LOS could be improved significantly. A longer timeframe for data analysis could reveal more stable lengths of

stay or possibly shorter lengths of stay with the continued implementation of this process.

\section{Recommendations for the Site}

Throughout the implementation of this project, recommendations for the site were evaluated for the continuation of this project and the potential implementation of future projects. The Deming Cycle or the Plan Do Study Act (PDSA) model served as a successful theoretical framework for the process implementation at the site. It would be recommended as a beneficial theoretic framework for any future comparable project implementation at this site.

Continuation of the project with an expansion on the screening criteria would be recommended for the site. A recommendation for the site practice moving forward is to include the patient's lowest blood pressure at the sending facility instead of the most current blood pressure. This suggestion is based on provider feedback and call analysis the recognized missed sepsis diagnosis based on blood pressure. It was recognized that patients were being screened as 
normotensive related to fluid boluses at the time of the transfer call but they were truly hypotensive prior to the fluid boluses and upon arrival the academic medical center.

For future project implementations, an improvement in the call management technology would be recommended for the site. The current call management technology had limited call data accessibility, it lacked interfacing capabilities with the electronic health record, it was limited in the storage space needed for call retrieval, and it failed to capture periods of call data.

A lack of adherence to standing policy at the transfer center was also recognized during the study period. During the study period adherence to the collection of standard vital signs and mental status were not completed on 25 patients in the first month, 15 patients in the second month, and 12 patients in the third month. Monthly call review and follow-up correspondence of call analysis were conducted throughout the study to improve adherence. A more vigorous schedule of call analysis, data collection, and feedback mechanism for all calls in the transfer center would also be recommended for this site. The performance measurement frequency recommended for the site includes an initial monthly evaluation during the change phase, quarterly evaluations after the aim or goal is achieved, and annually following the accomplishment of the goal and the establishment of stable performance (U.S. Department of Health and Human Services Administration, 2011).

\section{Recommendations for Other Settings}

The project implementation would be feasible for any patient transfer center due to the simplicity of the screening process. The project is scalable to any transfer center and the fundamental framework could be executed at any call center without the adoption of any technology or large expenditures. However, the project would be most effective for a similar size 
academic medical center with the available resources and expertise needed to answer the transfer line call and provide consultation 24 hours a day and 7 days a week.

The data evaluation process utilized for this project would require specific resources that may not be available in all other settings. A call management system or a comparable call recording process would be an important consideration for evaluation of the process. The electronic health record system would be a key consideration for another setting for data capturing during the evaluation of screening scores, best practices, time stamps, and patient outcomes evaluation. Also, a consistent technological platform and method for confirming the admittance diagnosis of patients is essential for the evaluation of the screening tool.

\section{Attainment of DNP Essentials}

\section{Essential I. Scientific Underpinnings for Practice.}

This project demonstrates substantial content for this essential as it sought to evaluate practice approaches from both nursing and medical evidenced based practice with underlying scientific underpinnings to improve care delivery for this critically ill patient population. The project was completed within a theoretic framework that guided its focus to integrate nursing and organization science to inform the practice change.

\section{Essential II. Organizational and Systems Leadership for Quality Improvement and Systems Thinking.}

This essential was met throughout the planning and implementation of this project. High level stakeholders from West Virginia's largest tertiary academic healthcare center were involved. The project systematically involved the development of policies and protocols, organizational 
education to support policy and protocol implementation, and leading the organizational change from beginning to end.

\section{Essential III. Clinical Scholarship and Analytical Methods for Evidence-Based Practice.}

During the implementation of this project, a thorough review of the literature and an analysis of evidenced based practices was completed to inform the practice change. The examination of the evidence informed the development of the project, the establishment of measures, and mechanisms for evaluating the project outcomes.

\section{Essential IV. Information Systems/Technology and Patient Care Technology for the Improvement and Transformation of Health Care}

This essential was used for all aspects of this project. The project required the use of three major IT systems for implementation and evaluation. During the implementation of this project two database builds were required for evaluation and a process was built within the electronic health record to complete the project's implementation. This use of IT was imperative to design this project and the ability of the project to improve the delivery of care for these patients.

\section{Essential V. Health Care Policy for Advocacy in Health Care.}

This project required a thorough evaluation of the organizations existing policies and collaboration with decision makers in the organization for a new policy implementation. A new policy was then designed and implemented that directed that practice change. From a broader standpoint, Federal regulations as defined by CMS recently added sepsis patient care to publicly reportable information with an ultimate link to hospital reimbursement. 


\section{Essential VI. Interprofessional Collaboration for Improving Patient and Population Health}

\section{Outcomes.}

This project required many disciplines to become stakeholders and participants in the process change. Physicians, Pharmacists, Researchers, Nurses, Administrators, Advanced Practice Professionals, and Executive leadership were pivotal to the successful completion of the development and implementation of the project. This essential was exemplified through the leadership of this interdisciplinary team to successfully implement this change project.

\section{Essential VII. Clinical Prevention and Population Health for Improving the Nation's Health.}

This project met this essential by focusing on the sepsis population and improving the health of these patients by influencing and incorporating a new care delivery model. Beyond the immediate academic health center, it serves a tertiary care center population through a significant region that may have improvements in health secondary to the implementation of this project. The new care delivery model served a region including 67 different facilities in 49 counties located throughout West Virginia, Kentucky, Virginia, Pennsylvania, and Ohio.

\section{Essential VIII. Advanced Nursing Practice.}

This essential was met through the assessment of a complex health situation and disease state and the design and implementation of an intervention to meet the needs of these patients. This required leading a healthcare team to change their practice, analysis of the complex results for clinical significance, and continual quality improvement of the practice change. 


\section{Appendix A}

\section{Sepsis Screening Process Algorithm}

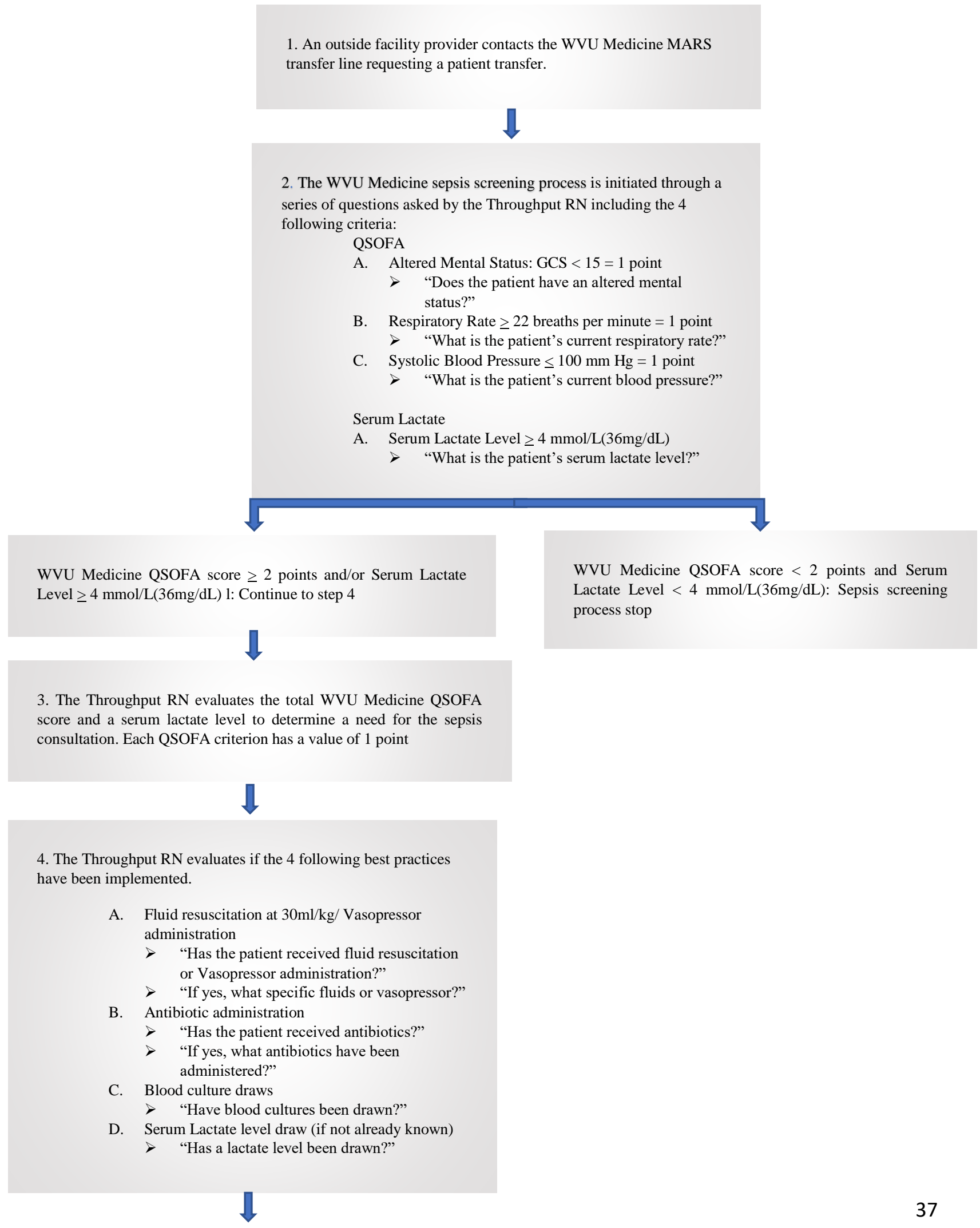


5. The Throughput RN contacts the WVU Medicine attending provider via the MARS transfer phone line.

\section{$\llbracket$}

6. The Throughput $\mathrm{RN}$ conveys the 4 best practices implementation status to the WVU Medicine attending provider.

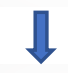

7. The Throughput RN connects the WVU Medicine attending provider with the outside facility provider via the MARS transfer line.

8. The WVU Medicine attending provider guides care to ensure that the following 4 best practices are completed as indicated:

A. Fluid resuscitation at $30 \mathrm{ml} / \mathrm{kg} /$ Vasopressor administration

B. Antibiotic administration

C. Blood culture draws

D. Serum Lactate level drawn

9. The Throughput $\mathrm{RN}$ completes the bed request.

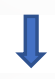

10. The patient arrives to WVU Medicine- Ruby Memorial. 


\section{Appendix B}

\section{Theoretical Framework: Deming Cycle, PDSA}

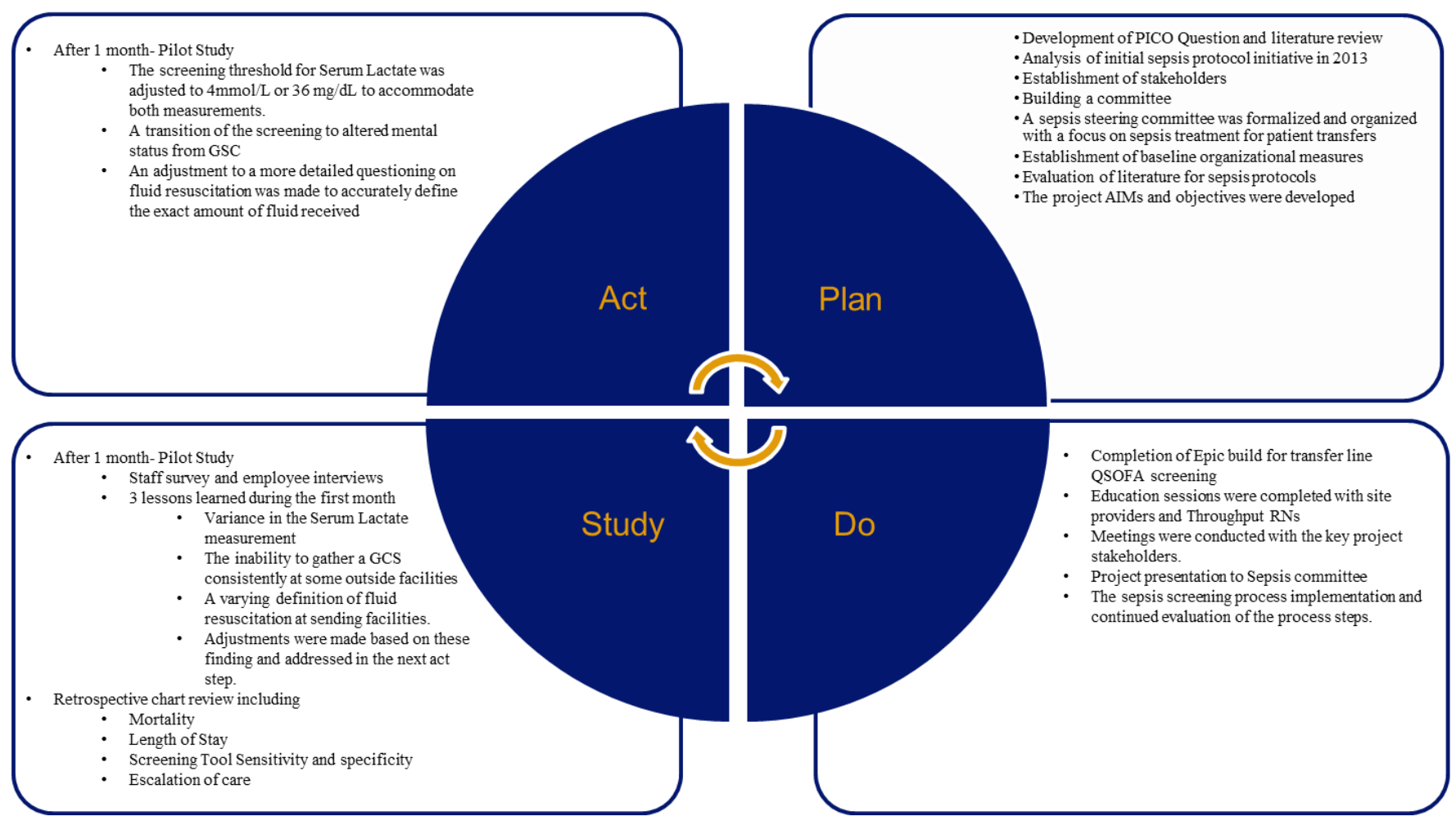




\section{Appendix C}

\section{Sepsis Screening Process Education}

What is a WVU Medicine QSOFA screen?

○ The "QSOFA" acronym stands for:

- Q-uick

- S-epsis Related Organ

- O-rgan

- F-ailure

- A-ssessment

What are the variables of a WVU Medicine QSOFA screen?

$\circ$ Altered Mental Status: GCS $<\mathbf{1 3}=1$ point

- "What is the patient's current GCS?"

$\circ \quad$ Respiratory Rate $>22$ breaths per minute $=1$ point

- "What is the patient's current respiratory rate?"

○ Systolic Blood Pressure $<\mathbf{1 0 0} \mathbf{~ m m ~ H g}=1$ point

- "What is the patient's current blood pressure?"

- Serum Lactate Level $>\mathbf{4} \mathbf{~ m m o l} / \mathrm{l}=1$ point

- "What is the patient's serum lactate level?"

How is a WVU Medicine QSOFA screen scored?

$\circ$ Each variable has a value of 1 point

A WVU Medicine QSOFA score < 2 points: Negative screen and the sepsis expert consultation is not indicated.

A WVU Medicine QSOFA score $\geq 2$ points: Positive screen and the sepsis expert consultation is indicated.

Who is performing the WVU Medicine QSOFA screening?

○ The WVU Medicine MARS line Throughput RNs.

When is the WVU Medicine QSOFA screen taking place?

$\circ$ During the patient information collection period at the onset of an adult patient transfer call from an outside facility.

What is WVU Medicine QSOFA screen replacing and why?

- What- QSOFA is replacing SIRS criteria screening.

- Why- According to the American Medical Association previous SIRS definitions included:

- An excessive focus on inflammation

- A misleading model that follows a continuum through severe sepsis to shock

- An inadequate specificity and sensitivity 
- Multiple definitions and terminologies that lead to discrepancies in reported incidence and observed mortality

What are the priority interventions of the Sepsis Consultation?

○ Fluid resuscitation/ Vasopressor administration

- "Has the patient received fluid resuscitation or Vasopressor administration?"

$\circ \quad$ Antibiotic administration

- "Has the patient received antibiotics?"

- "If yes, what antibiotics have been administered?"

○ Blood culture draws

- "Have blood cultures been drawn?"

- Serum Lactate level draw

- "Has a lactate level been drawn?"

When and how is the Sepsis Consultation initiated?

- When- Following the collection of a patient transfer's information when a WVU Medicine QSOFA score $\geq \mathbf{2}$ points exists

- How- A MARS telephone line connection is made between the sending provider and the attending physician.

What internal providers are serving as the Sepsis Consultants?

○ All on-call attending providers and fellows for their respective WVU Medicine services. 
Appendix D

\begin{tabular}{|c|c|c|}
\hline Budget Categories & Personal Funds & Organizational Contributions \\
\hline ADMINISTRATIVE COSTS & $\$ 0$ & $\$ 6,760$ \\
\hline \multicolumn{3}{|c|}{$\begin{array}{l}\text { Administrative Justification: Education of Throughput RN staff is essential for successful } \\
\text { integration of this process change. The education will be performed by } 2 \text { House supervisors } \\
\text { over a period of } 2 \text { total hours at approximately } \$ 40 \text { per hour }=\$ 160 \text {. Educational sessions will } \\
\text { occur over a } 1 \text { hour period for } 10 \text { Throughput } R N \text { at approximately } \$ 30 \text { per hour }=\$ 300 \text {. The } \\
\text { education will be supplementary to current organizational workflow and will be an } \\
\text { organizational contribution. Throughout the projects implementation period of } 3 \text { months, } \\
\text { there will be an additional } 2 \text { to } 10 \text { minutes per call for an average daily call volume of } 50 \text { calls } \\
\text { (estimated } 45 \text { calls at } 2 \text { minutes and } 5 \text { calls at } 10 \text { minutes) conducted by Throughput } \mathrm{RN} \text { staff } \\
\text { at an approximate } \$ 30=(\$ 1 \times 45 \text { calls } \$ 5 \times 5 \text { calls }) \$ 6,300 \text {. The added time spent during each } \\
\text { phone call will occur as an additional step during normal workflow and will be an } \\
\text { organizational contribution. }\end{array}$} \\
\hline Marketing & $\$ 0$ & $\$ 0$ \\
\hline \multicolumn{3}{|c|}{ Marketing Justification: } \\
\hline $\begin{array}{l}\text { EDUCATIONAL MATERIALS/ } \\
\text { INCENTIVES }\end{array}$ & $\$ 0$ & $\$ 50$ \\
\hline
\end{tabular}

Educational Materials/Incentives Justification: Materials needed for successful education and continued support of change process through provided reference materials. Materials needed include paper, posters, lamination sheets, and printer ink.

\begin{tabular}{|c|c|c|}
\hline $\begin{array}{c}\text { HOSPITALITY (food, room rentals, } \\
\text { etc.) }\end{array}$ & $\mathbf{\$ 0}$ & $\mathbf{\$ 5 0}$ \\
\hline
\end{tabular}

\begin{tabular}{|c|c|c|}
\hline \multicolumn{3}{|c|}{ Hospitality Justification: Refreshments for education sessions } \\
\hline $\begin{array}{c}\text { PROJECT SUPPLIES (office } \\
\text { supplies, postage, printing, etc.) }\end{array}$ & $\$ 0$ & $\$ 100$ \\
\hline
\end{tabular}

Project Supplies Justification: Current facility supplies already in place include computers, phones, and office space. Additional supplies needed including paper, folders, lamination sheets, printer ink, and 3 ring binders will be necessary as references to continually support the change.

\begin{tabular}{|cc|c|c|}
\hline TRAVEL EXPENSES & \$0 & \$0 \\
\hline \multicolumn{3}{|c|}{ Travel Expenses Justification: } \\
\hline
\end{tabular}




\begin{tabular}{|c|c|c|}
\hline OTHER & $\$ 0$ & $\$ 0$ \\
\hline \multicolumn{3}{|c|}{ Other Justification: } \\
\hline TOTALS & $\$ 0$ & $\$ 6,960$ \\
\hline
\end{tabular}




\section{Appendix E}

Sep-17Oct-17Nov-17Dec-17Jan-18Feb-18Mar-18Apr-18May-18Jun-18 Jul-18 Aug-18Sep-180ct-18Nov-18Dec-18

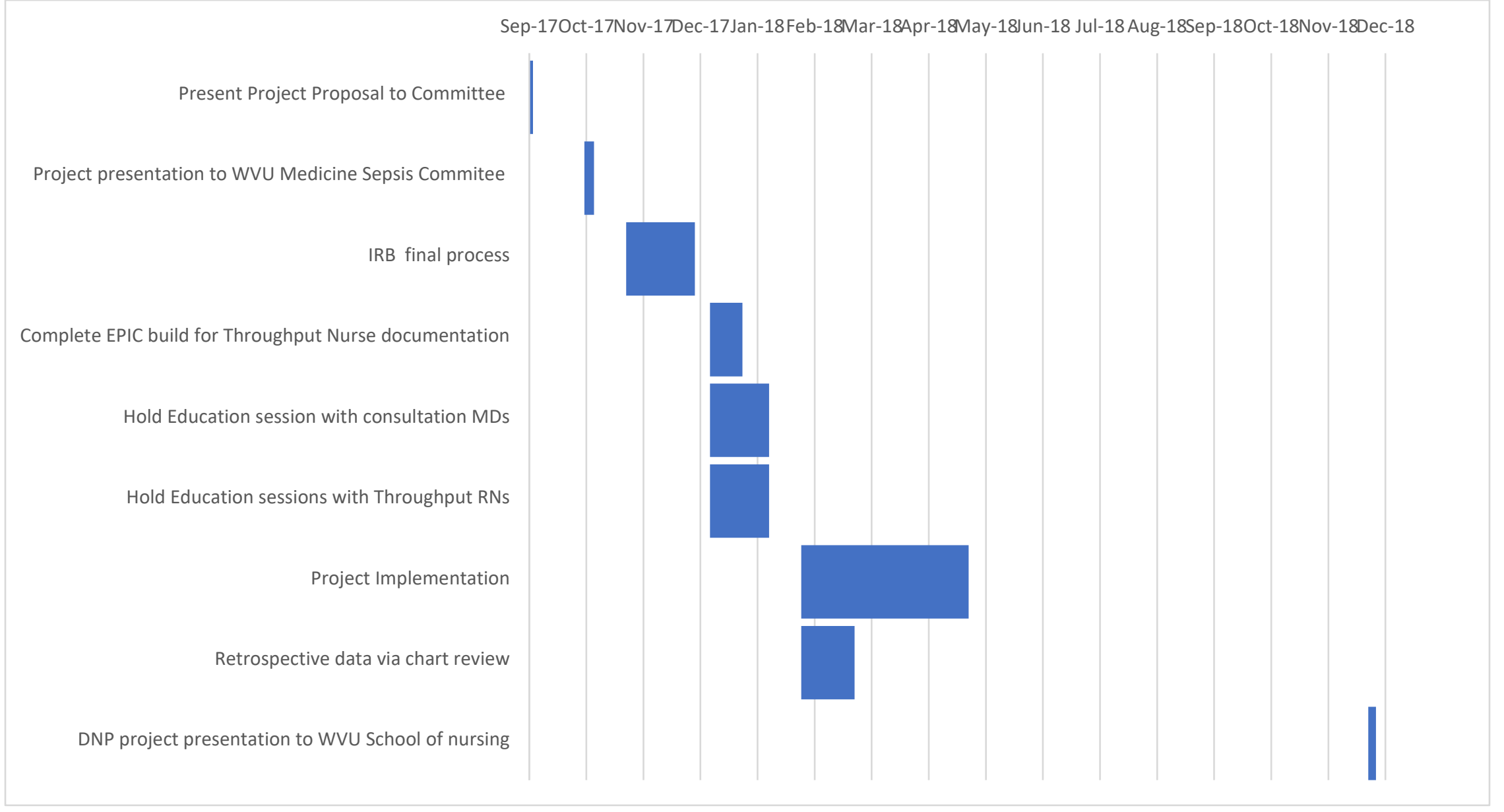




\section{Appendix F}

\section{Statistics}

Question guiding the statistical analysis:

- How does the pre-intervention group differ from the post-intervention group on length of stay (LOS), escalation of care (EOC), and mortality?

- H1: Compared to the pre-intervention group, the post-intervention group will have an increase in LOS.

- H2: Compared to the pre-intervention group, the post-intervention group will have a decrease in EOC and in mortality.

Descriptive statistics were run on the variables of LOS, EOC, and mortality in both the pre- and postintervention groups. Data were screened for missing data, incorrect values, and outliers. Table 1 presents descriptive data on these variables.

Table 1: Descriptive data on LOS, EOC, and mortality

\begin{tabular}{|l|l|l|l|}
\hline Group & LOS & EOC & Mortality \\
\hline $\begin{array}{l}\text { Pre-Intervention } \\
\mathrm{N}=244\end{array}$ & $\begin{array}{l}\text { Mean: } 12.77 \text { days } \\
\text { Median: } 9 \text { days } \\
\text { Mode: } 1 \text { day }\end{array}$ & $\begin{array}{l}\text { EOC } \text { Yes }=46 \\
\text { EOC No }=198\end{array}$ & $\begin{array}{l}\text { Yes }=74 \\
\text { No }=170\end{array}$ \\
\hline $\begin{array}{l}\text { Post-Intervention } \\
\mathrm{N}=225\end{array}$ & $\begin{array}{l}\text { Mean: } 14.84 \text { days } \\
\text { Median: } 10 \text { days } \\
\text { Mode: } 3 \text { days }\end{array}$ & $\begin{array}{l}\text { EOC } \text { Yes }=34 \\
\text { EOC No }=191\end{array}$ & $\begin{array}{l}\text { Yes }=50 \\
\text { No }=175\end{array}$ \\
\hline
\end{tabular}

\section{Length of Stay (LOS)}

To test $\mathrm{H} 1$, an independent samples t-test was used to compare the pre-intervention group to the postintervention group on LOS. There were no significant differences in scores for the pre-intervention group $(M=12.77, S D=12.33)$ and the post-intervention group $(M=14.84, S D=14.54) ; t(441)=-1.66, p$ $=.098$, two tailed). The magnitude of the difference in the means (mean difference $=2.07,95 \% \mathrm{Cl}:-4.53$ to 0.39 ) was very small (eta squared $=.006$ ). See Table 2 for output.

The Levene's test showed that the variances of the two groups are not the same $(p=.018)$, thus the SPSS output of equal variances not assumed was used, and showed a non-significant difference $(p=$ .098) between the two group on LOS.

The descriptive statistics showed that LOS increased by 2.07 days in the post-intervention group. In assessing for outliers, $91 \%$ of the cases in the pre-intervention group had a LOS of 32 days or less. The range of the remaining $9 \%$ was from 33-70 days. For the post-intervention group, $91 \%$ of the cases had a LOS of 38 days or less, with the remaining $9 \%$ having a range of 39-84 days. 


\section{Escalation of Care (EOC) and Mortality}

To test H2, a one-sample chi-square analysis was used to compare the proportion of cases in the postintervention group with those obtained previously from a comparison sample (the pre-intervention group). The expected values for EOC obtained from the pre-intervention group was $19 \%$; the expected value for mortality was $30 \%$.

A chi-square goodness-of-fit test indicates that there are not significant differences between the preintervention and the post-intervention groups on EOC (15.5\% compared to $18.9 \%$ in the pre-

intervention group) $\left[x^{2}(1, n=225)=2.21, p=.14\right]$; however, there are significant differences in mortality (22.2\% compared to $30 \%$ in the pre-intervention group), $x^{2}(1, n=225)=6.48, p=.01$. See Table 3 for output. 


\section{References}

Bone, RC., Balk., RA., Cerra., FB et al (1992). Definitions for Sepsis and Organ Failure and Guidelines for the Use of Innovative Therapies in Sepsis. Chest Journal, 101(6), 1644 1655.

Dellinger RP, Carlet JM, Masur H et al (2004) Surviving Sepsis Campaign Management Guidelines Committee. Surviving Sepsis Campaign guidelines for management of severe sepsis and septic shock. Intensive Care Med 30:536-555

Dellinger RP, Levy MM, Carlet JM et al (2008) Surviving Sepsis Campaign: international guidelines for management of severe sepsis and septic shock: 2008. Crit Care Med 36:296-327

Dellinger RP, Levy MM, Rhodes A et al (2013) Surviving sepsis campaign: international guidelines for management of severe sepsis and septic shock: 2012. Crit Care Med $41: 580-637$

Focht, A., Jones, A., \& Lowe, T.J. (2009). Early goal-directed therapy: improving mortality and morbidity of sepsis in the emergency department. The Joint Commission Journal on Quality and Patient Safety, 35(4), 186-191

Gaieski, D., Mikkelsen, M., Band, R.A., Pines, J., Massone, R., Furia, F., . . Goyal, M. (2010). Impact of time to antibiotics on survival in patients with severe sepsis or septic shock in whom early goal-directed therapy was initiated in the emergency department. Critical Care Medicine, 38(4), 1045-1053 
Hayden, G.E., Tuuri, R.E., Scott, R., Losek, J.D., Blackshaw, A.M., Schoenling, A.J., . . Hall, G.A. (2016). Triage sepsis alert and sepsis protocol lower time to fluids and antibiotics in the ED. American Journal of Emergency Medicine, 34, 1-9

Jones, S., Ashton, C., Bookout, J., Bookout, C., Kiehne, L., Gigliotti, E., \& Bell-Gordon, C. (2015). Reductions in sepsis mortality and costs after design and implementation of a nurse-based early recognition and response program. The Joint Commission Journal on Quality and Patient Safety, 41(11), 483-491

Levy MM, Dellinger RP, Townsend SR et al (2010) Surviving Sepsis Campaign. The Surviving Sepsis Campaign: results of an international guideline-based performance improvement program targeting severe sepsis. Crit Care Med 38:367-374

Levy MM, Rhodes A, Phillips GS et al (2015) Surviving Sepsis Campaign: association between

Narayanan, N., Gross, A.K., Pintens, M., Fee, C., \& MacDougall, C. (2016). Effect of an electronic medical record alert for severe sepsis among ED patients. American Journal of Emergency Medicine, 34, 185-188

Patel, G.W., Roderman, N., Gehring, H., Saad, J., \& Bartek, W. (2010). Assessing the effect of the surviving sepsis campaign treatment guidelines on clinical outcomes in a community hospital. The Annals of Pharmacology, 44, 1733-1738

Puskarich, M.A., Trzeciak, S., Shapiro, N.I., Arnold, R.C., Horton, J.M., Studnek, J.R., . . . Jones, A.E. (2011). Association between timing of antibiotic administration and mortality from septic shock in patients treated with a quantitative resuscitation protocol. Critical Care Medicine, 39(9), 2066-2071 
Rhodes A, Evans L, Alhazzani W et al (2017) Surviving sepsis campaign: international guidelines for management of sepsis and septic shock: 2016. Crit Care Med 45:486-552

Rhodes A, Phillips G, Beale R et al (2015) The Surviving Sepsis Campaign bundles and outcome: results from the International Multicentre Prevalence Study on Sepsis (the IMPreSS study). Intensive Care Med 41:1620-1628

Sepsis Alliance. (2016). Sepsis fact sheet. Retrieved from http://www.sepsis.org/downloads/2016_sepsis_facts_media.pdf

The Deming Institute. (2016). PDSA Cycle. Retrieved from https://deming.org/managementsystem/pdsacycle

Tromp, M., Hulscher, M., Bleeker-Rovers, C.P., Peters, L., Van Den Berg, D.T., Borme, G.F., . . . Pickkers, P. (2010). The role of nurses in the recognition and treatment of patients with sepsis in the emergency department: A prospective before-and-after intervention study. International Journal of Nursing Studies, 47, 1464-1473

Trzeciak, S., Dellinger, P., Abate, N., Cowan, R., Stauss, M., Kilgannon, H., . . Parrillo, J. (2006). Translating research to clinical practice: A 1-year experience with implementing early goal-directed therapy for septic shock in the emergency department. Chest Journal, 129(2), 217-218.

U.S. Department of Health \& Human Services. (2016). Sepsis. Retrieved from https://www.cdc.gov/sepsis/datareports/index.html

U. S. Department of Health and Human Services Health Resources and Services Administration. (2011). Managing Data for Performance Improvement. Retrieved from 
https://www.hrsa.gov/sites/default/files/quality/toolbox/508pdfs/managingdataperforman ceimprovement.pdf

Yealy, D.M., Kellum, J.A., Huang, D.T., Barnato, A.E., Weissfeld, L.A., \& Pike, F. (2014). A randomized trial of protocol-based care for early septic shock. The New England Journal of Medicine, 370(18), 1683-1693 